\title{
IMPROVEMENT OF ENERGY EFFICIENCY, RELIABILITY AND ENVIRONMENTAL SAFETY OF POWER PLANTS BASED ON ASSOCIATED PETROLEUM GAS
}

\author{
Oleg Borisovich Shonin', Roman Alekseyevich Salov ${ }^{1}$
}

1 Department of Electrical Engineering, Saint-Petersburg Mining University, $21^{\text {st }}$ Line 2, Saint-Petersburg 199106, Russia, e-mail: ninosh_eltech@mail.ru

Received: 2017.02.15

Accepted: 2017.03.07

Published: 2017.05.02

\begin{abstract}
The paper deals with one of important ecological problems - utilization of associated petroleum gas (APG) at oil fields. An example of APG usage as a fuel for gas turbine power plants is examined. Among possible topologies of power plants the focus is put on the structure based on turbines with combined diesel-gas supplying for increasing reliability of power generation in case of failures in the system of preparation of APG. In order to ensure correct transition of turbines from gas to diesel supplying it is important to know responds of the system to the interruption of gas supplying. Based on the fundamental principles of thermodynamics and fluid dynamics gas-turbine power plant simulation model has been developed utilizing MATLAB/Simulink environment. Using the model allowed revealing the influence of load-sharing among the turbines of different types on the transition to an additional source of turbine fuel. Based on simulation results, recommendations have been worked out for the improvement of the reliability of gas turbine power plant.
\end{abstract}

Keywords: gas turbine power plant; associated petroleum gas; fuel change; loadsharing.

\section{INTRODUCTION}

The oil and gas industry has been the main polluter of the air and environment due to the widespread flaring of large amounts of APG for many years. It accounts for about $30 \%$ of harmful emissions made by the entire industrial complex of Russia [Korzhubaev et al. 2012]. So, the problem of efficient utilization of associated petroleum gas (APG) at the oil fields is one of important ecological problems nowadays.

Many Russian oil and gas companies are taking steps to increase volume and energy efficiency of APG utilization in order to prevent global climate changes and reduce greenhouse gas emissions [Rosneft 2017, Surgutneftegas 2017]. These steps are undertaken under the requirements of environmentally safety documents adopted by the United Nations and ratified by many countries in the world including Russia [UNFCCC 2014].
It should be noted that drastic increase in pollution charges for gas flaring has greatly fostered seeking for rational ways of APG efficient utilization [Russian Federation government 2012]. These measures promote to forming a new policy targeted at rational and careful usage of energy minerals, which are annually reduced.

Today there are many different methods of APG utilization, some of them are:

- Usage of APG as a fuel for gas turbine power plants;

- APG processing in the feedstock for the petrochemical industry;

- Gas injection into the oil-containing reservoir for enhancing the oil extraction;

- Oil extraction by gas-lifting

- APG processing according to the GTL technology based on Fischer-Tropsch method.

The most advanced and energy-efficient technology of APG usage is to use it as a fuel 
in gas-turbine power plants (GTPP). GTPP generates electricity to meet the power demand of the oilfield equipment. Regarding the type of gas turbine plant (GTP) there is the following energy center structure: only mono-fuel turbines, turbines with combined fuel supplying, and power plant with two types of turbines.

Scientific issues related to the study of gas turbine power plants, their control systems and controlled modes of operation have been considered by a number of scientists such as Men'shov, Ershov [1995], Pershin [2006], Rowen [1983], Tavakoli [2009], Camporeale [1997] and many others.

However, the authors paid insufficient attention to the development of measures for improving the reliability of a standalone power plant based on the usage of dual fuel turbines. Consequently, elaboration of scientific methods for solution of that problem is a relevant task. The importance of study of the energy center operation based on APG is highlighted by the fact that in coming years the policy of oil companies in great extent will be defined by the necessity of APG utilization. This determines the scientific research topicality of solving environmental and energy problems.

This paper is dedicated to the research and analysis of the GTPP operation with turbines of combined fuel feeding. The research is aimed at the improvement of the system reliability via usage of a proposed method of the power plant load sharing among the generator units which enables to regulate the fuel demand for the involved turbines.

\section{STRUCTURE OF THE POWER PLANT BASED ON APG}

Functional diagram of the autonomous power plant on APG is shown in Figure 1.

The plant comprises a booster pump station (BPS) which is intended to compress the APG at the input of the gas preparation unit up to a pressure of 0.5 MPa. The gas treatment unit is intended for drying, cleaning and heating gas up to the appropriate conditioning level for feeding the APG to the gas turbine unit (GTU) in accordance with requirements specified by the manufacturer. After being processed the gas is supplied to the gas compressors one of which is in operation and the other in cold reserve. Compressors are used to create a pressure of $2.5 \mathrm{MPa}$ at the turbine inlet. Capacity of one compressor allows for feeding the fuel to four turbines simultaneously. After compression, the APG is led to the receiver in the capacity of a gas accumulator, and then to turbines. Under conditions of no controlled drive of the compressor, the required level of pressure is regulated by a pressure valve installed in a bypass line.

Automatic control system (ACS) ensures control of the processes of electrical power generation. ACS provides regulation of active and reactive power of synchronous generators, transition of gas turbines on additional fuel and also regulates pressure valve operation. Electrical power produced is supplied to $6 \mathrm{kV}$ bus and then transmitted to the consumers by overhead power lines.

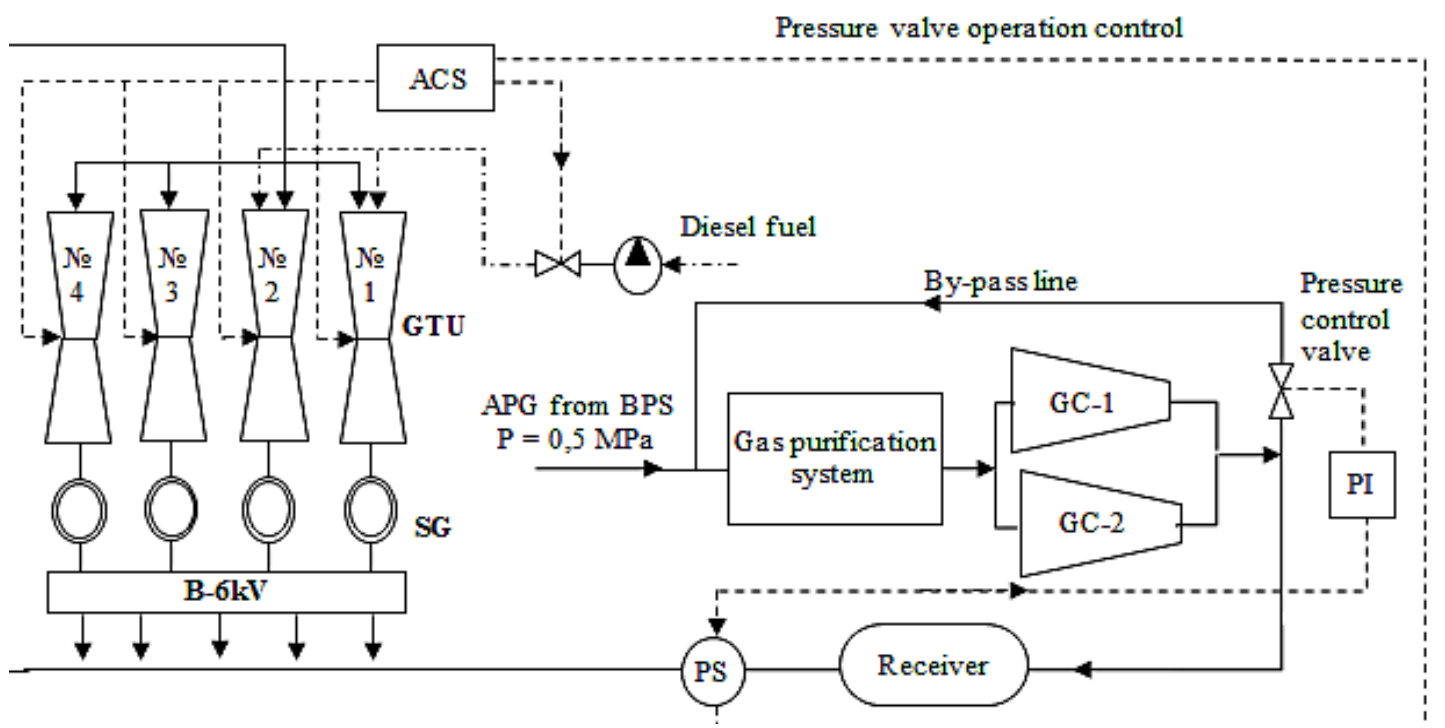

Figure 1. Structure of the power plant on APG, where BPS - booster pump station, GC - gas compressor, PI - proportional and integral controller, PS - pressure sensor, ACS - automatic control system, $\mathrm{SG}$ - synchronous generator, $\mathrm{B}$ - bus $6 \mathrm{kV}$ 
To improve the reliability of power supply of the customers, the power plant on APG is equipped with power turbines capable to work with both gas and diesel fuel. Transition from basic to additional fuel is initiated by ACS in case of failure in the gas processing and delivery system. If a subsystem that is responsible for changing a fuel type for turbines with double fuel supplying fails to ensure normal conditions of electricity generation the APG flaring begins.

Turbines SGT-100 «Typhoon», shown in the diagram under numbers №1 and №2, have the ability to run on two types of the above-mentionedfuel. Power plant capacity is about $30 \mathrm{MW}$.

\section{STUDY OBJECTIVE AND METHODOLOGY}

The main consumers of generated electric energy are oil production facilities such as:

- Asynchronous and synchronous drive of high power pump for oil extracting from the well,

- Reservoir pressure maintenance system, etc All these facilities demand power supply without failures [Men'shov et al. 2000].

However, during power plant operation there were emergency shutdowns of turbines with dual fuel due to an unsuccessful transfer from gas to diesel fuel. In connection with this the following problems arise:

- ensuring reliable transition from one mode of the turbine operation to another in case of gas compressor failure;

- ensuring a dynamical response of the fuel supply system for a quick load changing.

The hypothesis was put forward about possible impact of load-sharing among the turbines on the transition of fuel supply system from one type of the fuel to another.

The objective of research is in definition of the impact of GTPP modes on the fulfillment of required conditions for the transition from gas fuel to backup fuel. These conditions are preset in the algorithm of a control subsystem which is a part of ACS. Research of the processes in the GTPP under different conditions has been carried out with assistance of a simulation model developed in MATLAB/Simulink environment. A structure of the model is presented in Figure 2. Each component of the model is based upon the fundamental principles of thermodynamics and fluid dynamics.
For the compressor, relationship between pressure $\mathrm{P}$ and flow rate $\mathrm{Q}$ is expressed as follows [Cherkasskii 1984, Schmidt 2005]:

$$
\mathrm{Q}=\left(1-0,025\left({\frac{\mathrm{p}_{\mathrm{o}}}{\mathrm{p}_{\mathrm{i}}}}^{1 / \mathrm{m}}-1\right)\right) \lambda_{\mathrm{p}} \lambda_{\mathrm{L}} \mathrm{n}
$$

where $p_{0}$-output pressure, $\mathrm{Pa}$;

$p_{\mathrm{i}}$ - input pressure, $\mathrm{Pa}$;

$m$ - polytrophic coefficient;

$\lambda_{\mathrm{p}}-$ pressure coefficient; $\lambda_{\mathrm{p}}=0.95 \div 0.98$;

$\lambda_{L}^{\mathrm{p}}$ - leakage factor $; \lambda_{L}=0.95 \div 0.98$;

$V_{p}$ - working volume, $\mathrm{m}^{3}$;

$n-$ a number of double-strokes of compressor piston per minute.

The receiver of the APG is needed for smoothing pressure pulsations in the system. The fundamental equation for determining dynamic responses of the accumulator is the law of conservation of mass [Chernyi 1988]:

$$
\frac{\mathrm{dm}(\mathrm{t})}{\mathrm{dt}}=\mathrm{m}_{\mathrm{i}}-\mathrm{m}_{\mathrm{o}}
$$

where $m_{i}$ - input mass flow rate, $\mathrm{kg} / \mathrm{s}$;

$\mathrm{m}_{\mathrm{o}}$ - output mass flow rate, $\mathrm{kg} / \mathrm{s}$;

$m(t)$ - total mass of gas contained at time $t$.

The desired output signal from the receiver model is the instantaneous APG pressure $\mathrm{P}(\mathrm{t})$ at time t. By assuming ideal gas behavior and small deviations of the gas temperature, equation (2) can be rewritten as follows [Maxwell 2003]:

$$
\frac{\mathrm{dP}(\mathrm{t})}{\mathrm{dt}}=\frac{\left(\mathrm{Q}_{\mathrm{i}}-\mathrm{Q}_{\mathrm{o}}\right) \cdot \mathrm{P}(\mathrm{t})}{\mathrm{V}_{\mathrm{r}}}
$$

where: $P(t)$ - instantaneous gas pressure in the receiver, $\mathrm{Pa}$;

$V_{r}$ - receiver volume, $\mathrm{m}^{3}$;

$Q_{i}-$ input flow rate $\mathrm{m}^{3} / \mathrm{s}$;

$Q_{o}-$ output flow rate, $\mathrm{m}^{3} / \mathrm{s}$;

According to [Patrascioiu et al. 2009], valve performance under small changes in the system pressure can be presented by linear relationship:

$$
\mathrm{Q}=\mathrm{Q}_{0} \cdot \mathrm{h}
$$

where $Q$ - mass flow rate through the valve, $\mathrm{m}^{3} / \mathrm{s}$; $h=0-1-$ valve position.

Using approximation of data measured within operating range of the power plant, the relationship between input flow of gas turbines and GTPP output power can be expressed by a linear function [Boyce 2012]:

$$
\mathrm{Q}=\mathrm{Q}_{0}+\mathrm{k} \cdot \mathrm{P}
$$




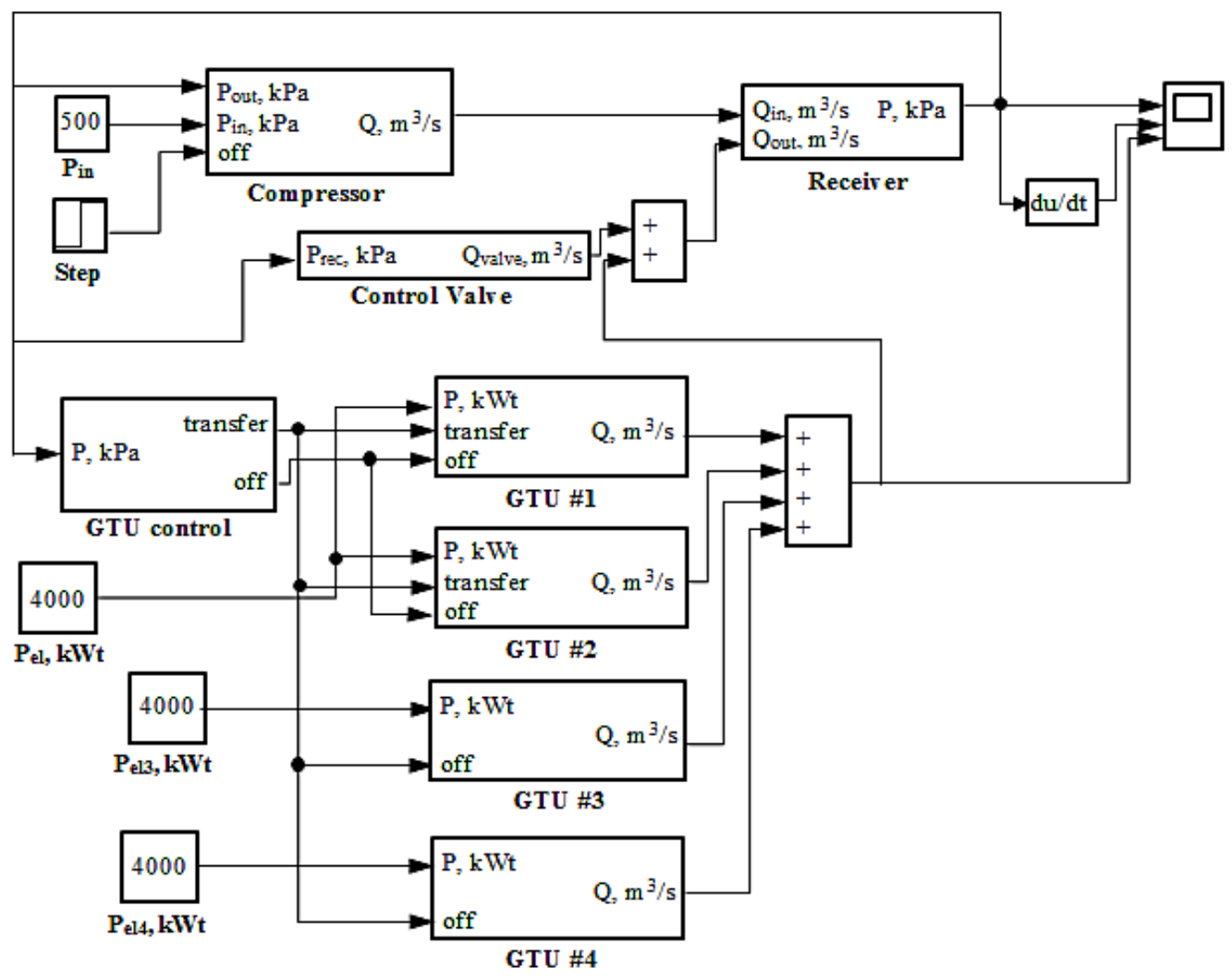

Figure 2. GTPP simulation model

\section{RESULTS AND DISCUSSION}

Upon occurring of failure in a gas purification unit, the turbine control system instructs the fuel supply system on switching the turbines from gas to diesel fuel. Activating the transition from gas fuel to liquid one and simultaneous disabling the conventional turbines begins when input pressure goes down up to $1800 \mathrm{kPa}$ and a pressure drop rate achieves $20 \mathrm{kPa} / \mathrm{s}$.

Investigation of the processes characterizing the transition of turbines on a backup fuel has been carried out for different initial conditions which found to be dependent on loading level of the turbines by synchronous generators.

Emergency situation was reproduced by a shut-down of the compressor. Operation of turbines under emergency conditions is described by the time dependences of residual input pressure $P_{\text {res }}(t)$ and the turbine demand in a gas flow $Q_{r e q}(t)$. The criterion for successful transition of the system to a backup fuel is a zero need for gas flow and a residual pressure above the critical value.

Consider the cases of successful and unsuccessful transition of the system to a backup fuel, using the plots of input pressure $P_{\text {res }}(t)$ and the turbine demand in a gas flow $Q_{\text {req }}(t)$ obtained for various examples of load-sharing of the power plant among the turbines of different types.

The graphs of successful transition of the turbines from gas fuel to diesel fuel are given in Figure 3, the graphs of unsuccessful transition - in Figure 4.

As it is seen from the plots, a shutdown of the compressor occurring at the time $t_{1}$ causes a gradual decrease in pressure in the receiver. When pressure reaches a set value, a signal for the control system to launch the transition process is formed. After the preparation comes to the end, the transition to diesel fuel is initiated at the time $t_{2}$. At the time $t_{3}$ the demand in gas fuel drops to zero at the pressure above critical level $P_{\text {res }}\left(t_{3}\right)>P_{C r}$ (Figure 3 ) and the transition is taken as successful. If the pressure drops to critical value $P_{\text {res }}\left(t_{3}\right) \leq P_{C r}$ (Figure 4) unsuccessful transition takes place, and the control system sends a signal to all the turbines for emergency stops.

Variation of power of turbines with a combined fuel supplying in the range of $0.5-4.5 \mathrm{MW}$ and variation of power of other types of turbines in the range of 1.0-7.5 MW at the given capacity of the power plant enabled obtaining a family of graphs similar to those ones shown in Figures 3 
and 4 . Those results were used to plot the curves reflecting the impact of loading the turbines on the residual pressure in the receiver (Figure 5).

As it is seen from figure 5a, increasing in the loading of turbines with a combined fuel supplying leads to a significant drop in residual pressure which is found to be not far from the critical value. Such a behavior of the residual pressure in the receiver under prevailing loading of the turbines with a combined fuel supplying can result in a long lasting transition to the backup fuel with a consequent failure in a successful transition.

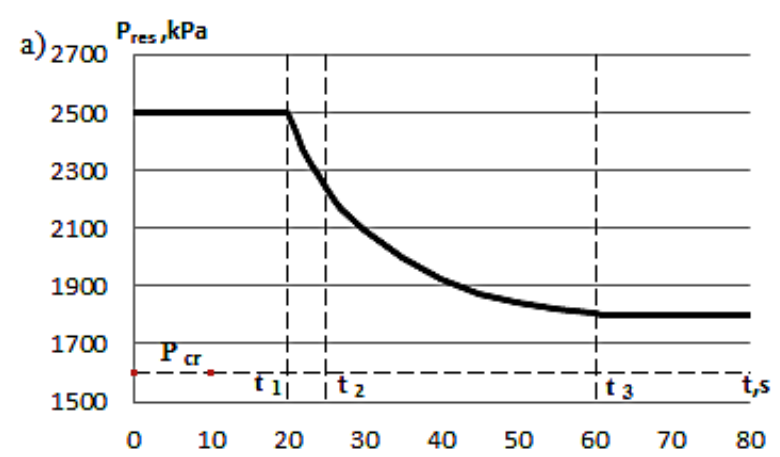

In its turn, an increase in loading of monofuel turbines leads to better conditions for successful transition of double-fuel turbines from gas to diesel supplying. This is due to the fact that after activating the transition from gas to liquid fuel and fast shut-down of conventional turbines, all the receiver capacity will be used for maintaining the transition process in turbines with double-fuel supplying according to the predetermined procedure.

On this basis, we can conclude that to ensure a successful transition to a backup power supply

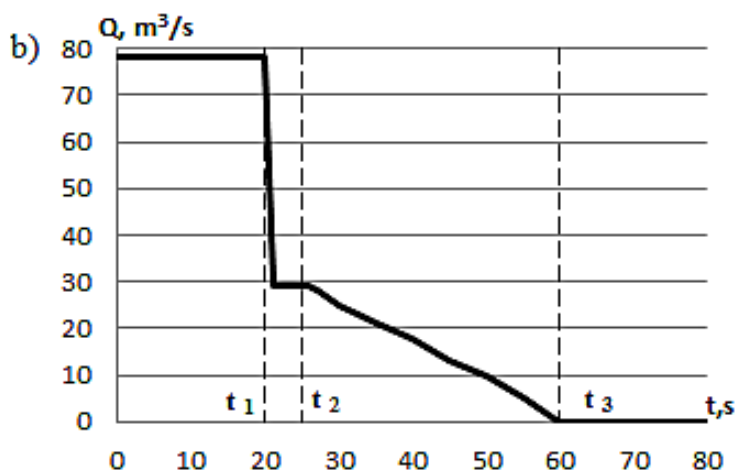

Figure 3. Change in pressure (a) and demand of the turbine for gas (b), when successful transition from APG to diesel fuel

a)

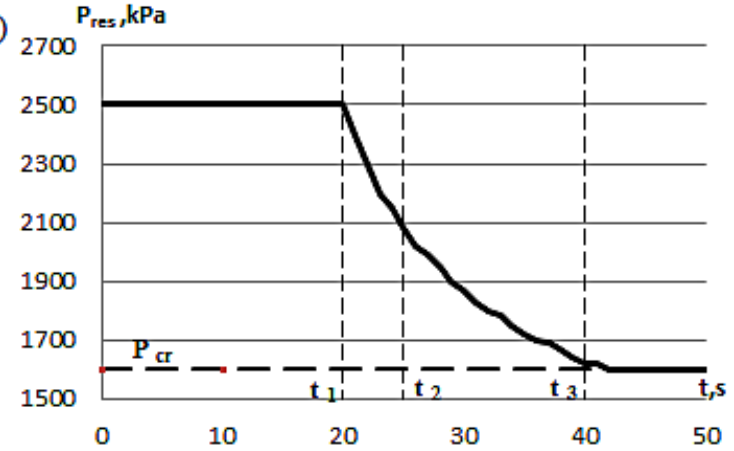

b)

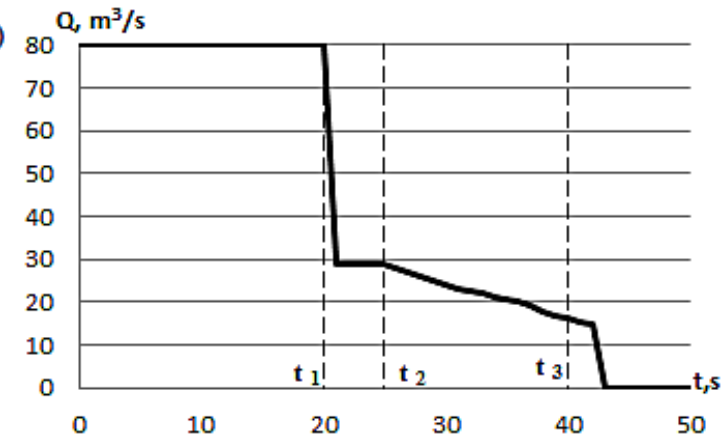

Figure 4. Change in pressure (a) and demand of the turbine for gas (b), when unsuccessful transition from APG to diesel fuel

a)

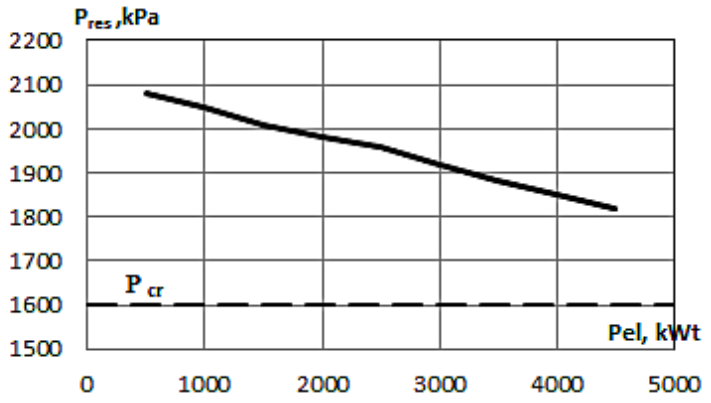

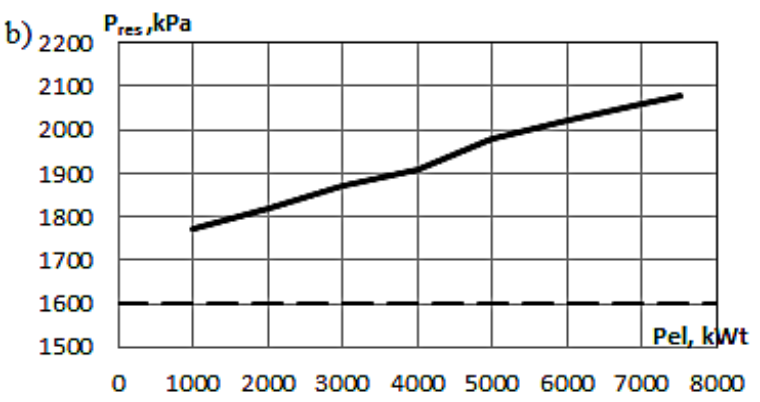

Figure 5. Dependences of a residual pressure in the receiver on the power generated by turbines with double fuel supplying (a) and conventional gas turbines (b) 
of the turbines the control system must share the generation of electricity among the turbines so that GTU with dual-fuel supplying were involved for covering the smallest share of the load.

Under conditions of load variations, ACS of GTPP should track down changing in power demand and regulate the system for efficient generation with keeping proper load sharing among the turbines for a successful transition to a backup fuel source in case of emergency.

\section{CONCLUSIONS}

Using the APG as a fuel for the gas turbine power plant allows oil companies to produce not only more energy for oil field equipment, but also to reduce the total cost of oil production because of the absence of the necessity to pay for other kind of energy. This method of APG utilization is the most effective and energy saving one among other methods. Not less importantly that such way of energy problem solution allows for simultaneous reducing the emission of pollutants into the atmosphere leading to environmental improvement.

Unfortunately, faults in operation of the APG turbine power plant cause the necessity of APG flaring. There is therefore a need to improve the reliability of the power plant on APG in order not only to ensure the uninterruptable power supply of oil field machinery but also to diminish the risk of environment pollution.

The research results presented in this paper allowed revealing the factors affecting the reliability of the energy center on associated petroleum gas. It was shown that load sharing among the turbines of different types is an important factor influencing the conditions of successful transition to a backup fuel supply in case of faults in APG preparation system. Practical recommendations to improve the reliability of the APG power station by regulating the system for appropriate load sharing among the turbines have been worked out. These recommendations can be used by oil companies for the development of technical regulations for ensuring the reliable operation of power stations on APG.

\section{REFERENCES}

1. Boyce M.P. 2012. Gas Turbine Engineering Handbook - Fourth Edition. Elsevier, UK.
2. Camporeale S.M., Fortunato B. 1997. Dynamic analysis and control of turbo-gas power plant. Proc. Energy Conversion Engineering Conference, 1702-1707.

3. Cherkasskii V.M. 1984. Pumps, fans, compressors. Jenergoatomizdat, Moscow.

4. Chernyi G.G. 1988. Fluid dynamics. Nauka, Moscow.

5. Russian Federation government. 2012. About features of the calculation of a payment for the emissions of the pollutants, which are formed from utilization of associated petroleum gas through the flaring and (or) its dispersion. Russian business newspaper, 873(44), 7.

6. Korzhubaev A.G., Lamert D.A., Eder L.V. 2012. Associated petroleum gas effective use's problems and prospects in Russia. Drilling and oil, 04, 4-7.

7. Kyoto Protocol. Official web site of the United Nations Framework Convention on Climate Change (UNFCCC). URL: http://unfccc.int/kyoto_protocol/items/2830.php (accessed: 18.02.2017).

8. Maxwell R. 2003. Dynamic simulation of compressed air systems. Proc. ACEEE Summer Study on Energy Efficiency in Industry, 146-156.

9. Men'shov B.G., Ershov M.S. 1995. The electric reliability of gas-turbine compression stations. Nedra, Moscow.

10. Men'shov B.G., Ershov M.S., Yarizov A.D. 2000. Electrical facilities and complexes in the oil and gas industry. Nedra, Moscow.

11. Patrascioiu C., Panaitescu C., Paraschiv N. 2009. Control valves - modeling and simulation. Proc. WSEAS international conference on dynamical systems and control, 63-68.

12. Pershin P.I. 2006. Building the mathematical model of multi-component gas turbine power plant for the purposes of research and control algorithms optimization. Ph.D. Thesis, Saint-Petersburg Polytechnic University, Saint-Petersburg.

13. Rosneft official web site. URL: https://www.rosneft.com (accessed: 18.02.2017).

14. Rowen W.I. 1983. Simplified mathematical representations of heavy-duty gas turbines. Journal of Engineering for Power, 105(4), 865-869.

15. Schmidt C. 2005. Modeling and simulation of air compressor energy use. Proc. ACEEE Summer Study on Energy in Industry, 131-142.

16. Surgutneftegas official web site. URL: http://www. surgutneftegas.ru/en/ecology/ (accessed: 18.02.2017).

17. Tavakoli M.R.B., Vahidi B., Gawlik W. 2009. An educational guide to extract the parameters of heavy duty gas turbines model in dynamic studies based on operational data. IEEE Transactions on power systems, 24(3), 1366-1374. 